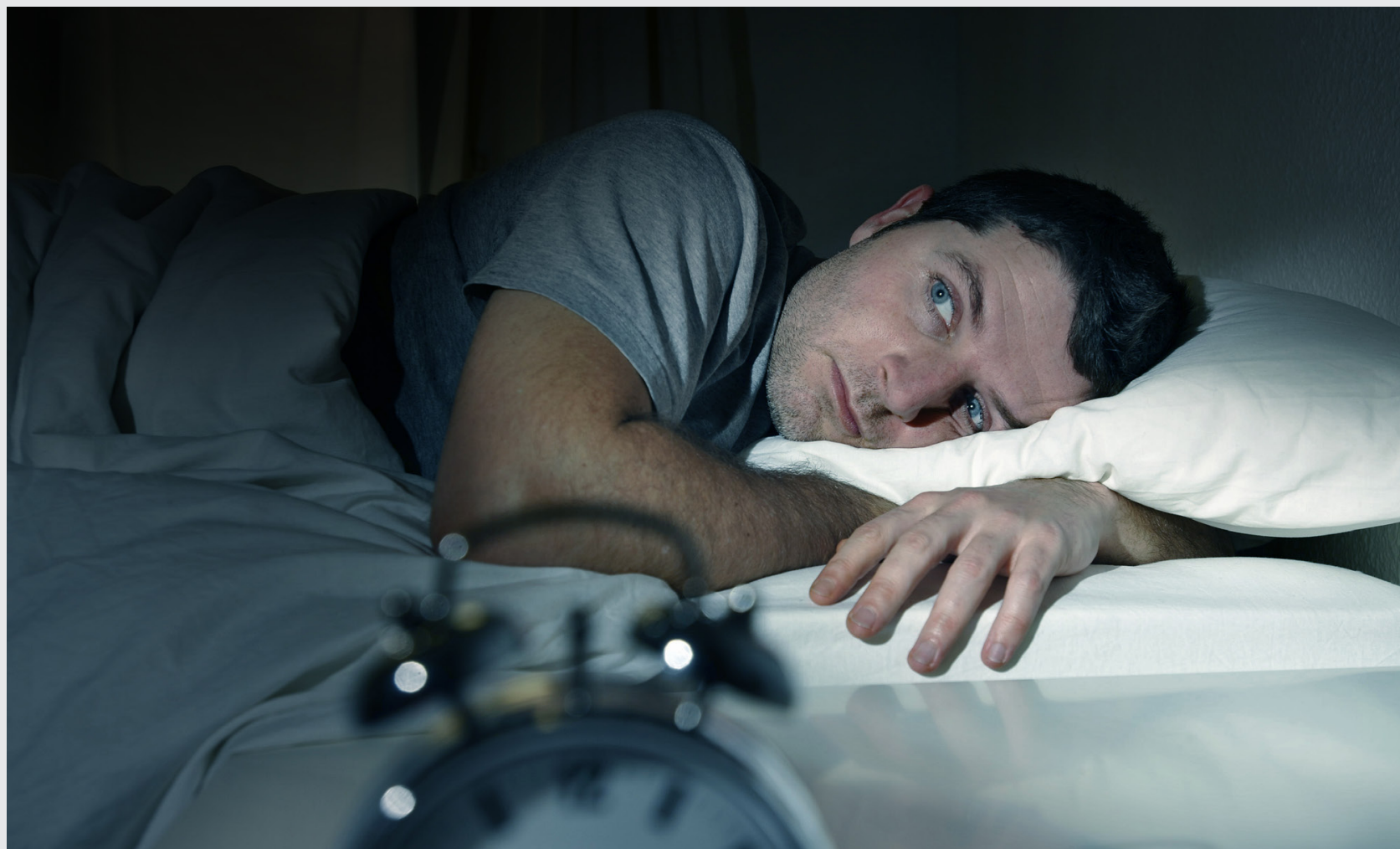

\title{
VOCÊ TEM MEDO DE QUÊ?
}

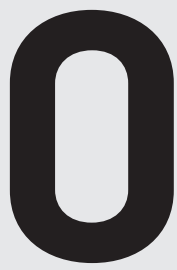

medo é um tema que não aparece à toa nas discussões sobre a sociedade contemporânea. $\mathrm{O}$ mundo atual é cada vez mais atravessado por uma crise de nossas certezas. Se sob muitos aspectos as últimas décadas trouxeram avanços, por outro lado também trouxeram insegurança: o mundo se tornou um lugar mais instável e imprevisível, em que nos vemos diante de maiores riscos em nossas relações, interações e decisões. Esse quadro faz com que o medo, um dos sentimentos mais antigos e atávicos do ser humano, esteja na ordem do dia.

Entender o medo na sociedade é um grande empreendimento. Com o intuito de dar uma pequena contribuição para esse debate, uma recente pesquisa realizada por professores da FGV/EAESP, em parceria com a Universidade Federal da Bahia, teve como objetivo identificar os principais medos sociais dos brasileiros na atualidade. Para tanto, os professores Maria Ester de Freitas, da FGV/EAESP, e Marcelo Dantas, da UFBA, coordenaram uma sondagem nas cidades de São Paulo e Salvador. 1380 pessoas de diferentes idades, gêneros e condições socioeconômicas foram entrevistadas e responderam, em última análise, uma questão muito simples e direta: "Você tem medo de quê"?

A escolha dessas cidades foi motivada pelo interesse em identificar se haveria diferenças nas percepções e opiniões entre as pessoas que moram em São Paulo, região mais urbana e desenvolvida do país, e em Salvador, capital de um dos estados de maior população rural e que faz parte da região Nordeste, uma das mais pobres do Brasil.

\section{TAXONOMIA DO MEDO}

Considerando que o interesse da pesquisa era centrado em algo de caráter coletivo - o medo do brasileiro de forma geral -, os respondentes se abstiveram espontaneamente de citar medos de foro íntimo ou existencial, colocando o foco em medos mais objetivos. Os resultados, submetidos a técnicas estatísticas de agrupamento, resultaram em sete grandes tipos de medo, sintetizados no quadro da página seguinte, em geral relacionados a necessidades básicas de sobrevivência e segurança do dia-a-dia: 
Ser vítima de crimes, ter que viver trancado para se proteger, sentir-se impotente frente à violência e não conseguir proteger a família e os filhos de situações perigosas, inclusive das drogas.

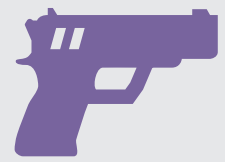

MEDO DA VIOLÊNCIA URBANA
Insuficiência na prestação de serviços de saúde, medo de morrer na fila de um hospital público, ver o futuro dos filhos comprometido, não ter moradia decente, precisar da justiça, medo da corrupção, da impunidade e da qualidade dos políticos.
Falta de emprego, passar fome ou não ser capaz de suprir as necessidades da família, cair de nível social, viver na pobreza, retorno da inflação e perda da poupança familiar.

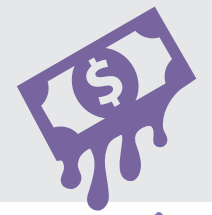

MEDOS ECONÔMICOS

\section{MEDO DA PERDA}

DE SENTIDO DA VIDA

Solidão, não ter amigos, não ter mais motivos para sorrir, morrer sem aproveitar a vida, ser discriminado e objeto de preconceito, ser excluído do grupo social, perder a liberdade, ser infeliz, não ter mais sonhos e esperança, precisar ficar longe do país.

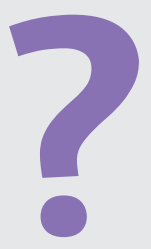

\section{MEDO DO FUTURO INCERTO}

Perder conquistas e direitos adquiridos, de que os filhos não tenham a chance de ter um futuro melhor, de envelhecer desamparado, de nunca conseguir melhorar de vida, de não ter um futuro digno, de nunca parar de trabalhar, da aposentadoria, de se arriscar.

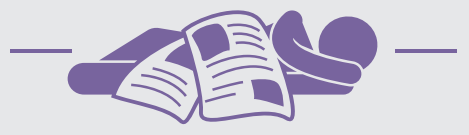

MEDO DO DESAMPARO DO ESTADO

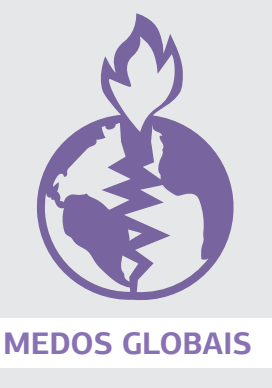

MEDOS GLOBAIS

De catástrofes naturais, guerras, de não cuidarmos ou perdermos patrimônios como a Amazônia.

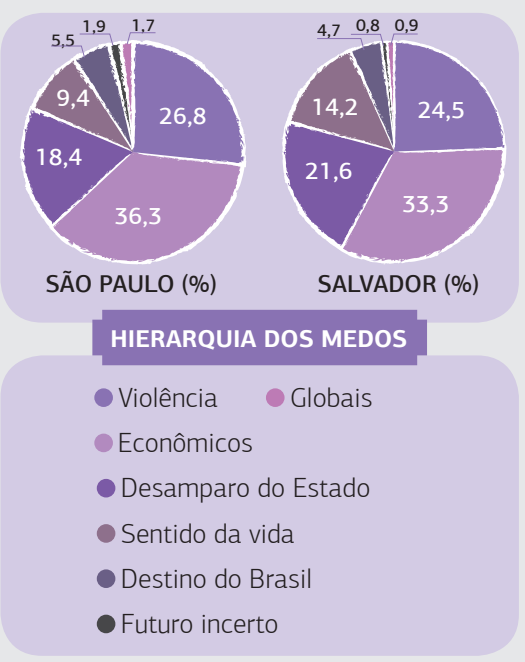

\section{HIERARQUIA DOS MEDOS}

Tão importante quanto conhecer os diferentes tipos de medo do brasileiro é saber a sua importância relativa, ou seja, as frequências com que foram manifestados pelos respondentes da pesquisa. A esse respeito, como mostram os gráficos acima, um dos principais resultados do estudo foi a ausência de diferenças significativas entre os respondentes das duas cidades: no agregado, paulistas e baianos sentem medo das mesmas coisas.

Chama a atenção também a predominância clara de dois grupos de medo: os econômicos e da violência, que juntos correspondem a mais de $50 \%$ dos medos revelados na pesquisa.

Por último, um dado curioso: seja em São Paulo ou em Salvador, dos respondentes que manifestaram medos relacionados ao destino e à imagem do Brasil, boa parte os associou a preocupações com a Copa do Mundo de 2014. O detalhe parece dizer algo significativo sobre nós: até no medo, o Brasil é o país do futebol!

\footnotetext{
PARA SABER MAIS:

- Medos sociais dos brasileiros. Maria Ester de Freitas e Marcelo Dantas. Revista Organizações e Sociedade (Salvador), vol. 21, nº 68, janeiro-julho 2014.
} 